\section{Update on animal welfare per- ception by Italian consumers: A descriptive survey}

\author{
Giulia Rubini, ${ }^{1}$ Eleonora Nannoni, ${ }^{1}$ \\ Jorgelina Di Pasquale, ${ }^{2}$ \\ Giovanna Martelli, ${ }^{1}$ Luca Sardi ${ }^{1}$ \\ ${ }^{1}$ Department of Veterinary Medical \\ Sciences (DIMEVET), University of \\ Bologna, Ozzano Emilia (BO); ${ }^{2}$ Faculty \\ of Veterinary Medicine, University of \\ Teramo, Italia
}

\begin{abstract}
The aim of this study was to evaluate if and how the perception of animal welfare by Italian consumers and their purchasing behavior of animal-friendly foods have evolved in recent years. The research was carried out through a survey on a representative sample of Italian consumers $(n=969)$. Responses showed that $69 \%$ of consumers declared to pay attention to animal welfare at time of purchasing, and they mostly acquired information about animal welfare through the mass media. In accordance with previous surveys, the categories perceived as having the highest welfare level were fish and dairy cows, whereas the lowest welfare level was attributed to broilers and pigs. Compared to previous surveys, Italian consumers seem to have improved their knowledge about the legislation on animal protection and increased their interest toward animal welfare issues. However, they still find it difficult to identify animalfriendly labels, together with a lack of knowledge about non-conventional (e.g. extensive and organic) farming systems.
\end{abstract}

\section{Introduction}

The quality of animal products is judged by economically developed societies also in relation to the ethics of their production strategies, including the impact on animal welfare and its possible consequences on food safety. Since genetic selection and management for high productivity may lead to more disease and poor welfare, consumers demand some major changes in animal-production systems (Broom, 2010). In this framework, Goldberg in 2016 defined the concept of "sustainable intensification" and suggested that if the welfare of farmed animals is improved, many of the human health consequences of intensified industrial production can be eliminated or reduced. Therefore, animal welfare fully becomes one of the elements of the broader "One Health" approach.

Besides of the ongoing public debate about how farm animals should be treated, the issue related to which information on animals living conditions labels should convey still remains open (Vanhonacker and Verbeke, 2014; Clark et al., 2017; Mancini et al., 2018). Regulatory options should reflect public priorities, expectations and requirements (Bennett et al., 2012; FAWC, 2014).

At a national level, the declared interest of Italian consumers towards animal welfare is not always reflected in a transparent communication strategy and, to date, it is still difficult to identify animal-friendly products (i.e., products obtained under production schemes requiring levels of animal protection above the minimum mandatory levels) (EC, 2005; Di Pasquale et al., 2014). The situation is further complicated by the spreading on the market of several private labels referring to animal welfare that often do not contain any specific indications on the rearing methods. For this reason, the effort being made at European level to develop transparent labeling that helps consumers to recognize foods obtained through greater respect for animal welfare, becomes of fundamental importance (Council of the European Union, 2020).

The aim of the present work was to investigate the case-study of Italian consumers and to provide an update on their perception of animal welfare and on their purchasing behavior with respect to animalfriendly foods. The results of the present research are compared with the outcomes of Eurobarometer surveys (EC 2005, 2007 and 2016) and with those from a previous study on a smaller, local sample of citizens living in Bologna area (Di Pasquale et al., 2014) to assess if and how Italian, consumers perception of animal welfare has changed over the past years.

\section{Materials and methods}

A survey was carried out in Italy, between December 2018 and January 2019 by using the questionnaire reported by $\mathrm{Di}$ Pasquale et al. (2019).

Interviewees were contacted by a specialized agency (DemetraOpinioni.net S.r.l., Venice, Italy), with CAWI (Computer Assisted Web Interview) methodology. Overall, 1463 invitations were sent. Participation was voluntary and the information collected was processed and used completely anonymously after collecting the consent of the respondents.

The sample obtained was representative
Correspondence: Eleonora Nannoni, Department of Veterinary Medical Sciences, Via Tolara di Sopra 50, 40064 Ozzano Emilia (BO), Italy.

Tel.: +39.0512097382

E-mail: eleonora.nannoni2@unibo.it

Key words: Animal Welfare, Consumer Perception, Survey.

Contributions: The authors contributed equally.

Conflict of interest: The authors declare no conflict of interest.

Funding: None.

Availability of data and materials: All data and materials are available within the text.

Received for publication: 7 January 2021.

Revision received: 7 July 2021.

Accepted for publication: 30 August 2021.

This work is licensed under a Creative Commons Attribution-NonCommercial 4.0 International License (CC BY-NC 4.0).

(C) Copyright: the Author(s), 2021

Licensee PAGEPress, Italy

Italian Journal of Food Safety 2021; 10:9588

doi:10.4081/ijfs.2021.9588

of the Italian population for gender, age (over 18 years) and geographical area (ISTAT, 2018). The questionnaire started with a socio-demographic section. A second section (14 questions) focused on consumer background (meat consumption habits, previous farm visits, attitude and perception towards the welfare of farmed animals) and knowledge (of animal protection laws and of animal-friendly foods).

Data are presented and discussed through a descriptive analysis.

To avoid redundancies, from this section of the text onwards the study by $\mathrm{Di}$ Pasquale et al. (2014) will be referred as "the previous 2014 study".

\section{Discussion}

Of the 1062 responses received, 93 were excluded (vegans, vegetarians, or consumers providing incomplete/partial answers), therefore the sample consisted of 969 respondents.

\section{Socio demographic information and declared purchasing habits}

Respondents were equally distributed between men (50\%) and women (50\%). Age class between 39 and 59 years was the 
most represented (44\%), followed by the range $18-39$ years $(33 \%)$. With respect to education, only a few interviewees had low educational level (primary or secondary school, 10\%), the majority had a high school diploma (55\%) and $35 \%$ had a university (or higher) degree.

As regards employment, the three most represented categories were employees $(26 \%)$, homemakers $(11 \%)$ and retirees $(11 \%)$. Students represented approximately $10 \%$ of the sample. Respondents lived mostly in urban centers (87\%), with $49 \%$ out of them living in small-medium size cities (10 to 100 thousand inhabitants).

With respect to annual household income, $21,000-35,000 €$ was the most represented range (35\% of the respondents), followed by the $11,000-20,000 €$ range ( $23 \%$ of respondents), and by the 35,000-50,000€ range $(22 \%)$; lastly, the lowest income range (below $10,000 €$ ) included $10.5 \%$ of the interviewees and the remaining $9.5 \%$ were the wealthiest consumers $(51,000$ $75,000 €)$.

Overall, the socio-demographic characteristics of the sample are similar to those reported in the local previous 2014 study carried out in the area surrounding Bologna. The only differences between the two studies consists in consumers in the present study having a lower percentage of university degrees ( $35 \%$ vs. $45 \%)$, and an overall lower income level. These two differences can be explained by the fact that Bologna hosts an important university and that Emilia Romagna is one of the Italian regions having the highest income per capita (ISTAT, 2019).

No effect of the area of residence was observed on the importance that consumers attribute to animal welfare at the time of purchasing, with consumers living in urban areas assigning (on a 0-to-10 scale) an average score of 7.5, and those from extra-urban areas a score of 7.7. Since this kind of question may elicit a social desirability bias (a well described psychological phenomenon in which the interviewed tends to answer in order to please the interviewer or to appear in the most favorable light -Nowwood and Lusk, 2011), we proposed a wider scale in order to differentiate between the answers, that we were expecting to fall in the higher half of the scale for the large majority.

Consumers were then asked how often they do buy animal-friendly foods (i.e., products obtained respecting higher animal welfare standards compared to the minimum set up by legislation). Their answers did not differ depending on the area of residence: in both urban and non-urban groups, a significant proportion $(41 \%$ and $43 \%$, respectively) declared to buy animal-friend- ly products only sometimes, and $28 \%$ claimed to buy them always. Less than one third of respondents declared to never buy these products.

\section{Knowledge of animal welfare}

Consumers were asked if they had ever heard about animal welfare previously, and $78 \%$ said they did. This figure substantially differs from the previous 2014 study, in which only $65 \%$ of the respondents had heard before about animal welfare. This difference may be due to greater attention paid by media towards this issue in recent years and to the subsequent increased consumer concern, as already pointed out by the 2016 Eurobarometer (EC, 2016) in which most Europeans (94\%) believed that it was important to protect the welfare of farmed animals.

As concerns the source of information about conditions under which farm animals are kept, most respondents indicated mass media and internet (66\%), which were confirmed to be over the years the main sources through which consumers get information ( $68 \%$ in the previous 2014 study). The other main source of information was visiting farms ( $11 \%$ of the sample had visited a farm at least once).

\section{Perception of animal welfare}

Those who have acquired direct knowledge of the conditions of the animals through visits to farms assigned, on a 0 -to10 scale, a slightly higher score (7.8) to the importance of animal welfare in their purchasing choices compared to the overall average (7.5). Despite the two questions might not be fully comparable (on the one hand the psychological attitude and on the other hand the economic intention to spend more is investigated), this result does not seem to fully agree with the 2005 Eurobarometer (EC, 2005), in which mainly consumers having repeatedly visited farms were more willing to pay the highest premium price $(+25 \%)$ for animal-friendly eggs. Our results can be explained by the fact that nowadays more consumers, due to media campaigns and regardless of their direct experience, may be interested and concerned about animal welfare, therefore opting more easily for "animal-friendly" foods when the animal welfare content is made explicit to the consumer. As discussed in the "purchasing behavior" section, a peculiar consideration applies to the organic method. These products, in fact, are generally marketed using claims about their overall quality rather than their animal-friendliness. Therefore, their animal welfare content is in fact only marginally known by consumers.

Respondents were also asked to indicate (on a 1-to-5 scale) the perceived level of welfare on farms of different species/production categories (Figure 1). Species/categories perceived as having the highest welfare level were fish and dairy cows. The category showing the lowest welfare level was broilers $(22 \%$ of respondents assigned the minimum welfare score and $27 \%$ a value just above). The welfare level of pigs was also perceived as low: $15 \%$ of consumers attributed score 1 and $25 \%$ a score of 2 . These responses reflect those reported in previous surveys (Di Pasquale et al., 2014; EC, 2005). On average, dairy cow welfare level was scored 3.2, followed by the welfare of fish (3.1), beef cattle (3.0), pigs and laying hens (2.7), and broilers (2.5).

To further assess consumers knowledge, we asked which, in their opinion, are the essential factors affecting animal welfare level (Figure 2). The most frequent answer ( $86 \%$ of consumers) was 'availability of space', and this result agrees with the previous 2014 study. The second most important factor (identified by $78 \%$ of respondents), was the 'possibility for animals to express their natural behaviors'. 'Access to outside areas', 'adequate transport' and 'absence of mutilations' were equally important factors for consumers (approximately $65 \%$ of the interviewees), immediately followed by 'presence of trained stock-people' (58\%). These answers reveal that consumers have a clear view on which needs must be met in order to attain a high welfare level; however, this awareness is in contrast with the observed insufficient knowledge of the characteristics of the different production systems and chains (see below).

Contrarily, it is interesting to note that a study carried out almost twenty years ago in Italy (Miele et al., 2001), had shown that, for Italian consumers, the main aspect to be safeguarded against welfare was 'quality of feed'. However, it should be remembered that the end of the 20th century coincided with the 'mad cow disease' scandal, which drew great attention to animal feeding practices and their effects on human and animal health.

Consumers were also asked to answer the question 'Which production phases are regulated by laws on animal protection?' (multiple answers were allowed). Most consumers $(66 \%)$ believed all stages of the process (farm, slaughtering and transport) being regulated, $20 \%$ were aware of the existence of laws regulating animal farming, 19\% feeding, 14\% slaughtering and $12 \%$ transport. Only $5 \%$ of the respondents were unaware of any legislation on animal protection. These results deeply differ from those obtained from previous surveys. In 2005, 19\% of European consumers (and 
$17 \%$ of Italian ones) were unaware of any legislation on farm animal protection (EC, 2005). In the previous 2014 study, $34 \%$ of Italian consumers believed that no production phase was regulated. Albeit with the necessary cautions in comparing surveys carried out on samples of different size and geographical location, these so discordant data might suggest a positive evolution in the knowledge of Italian consumers, possibly indicating also a better awareness regarding the law in comparison with the situation encountered previously.

\section{Purchasing behavior}

In the present survey, $69 \%$ of consumers declared to pay attention to animal welfare at time of purchasing (as above mentioned, $28 \%$ declares to always buy animal-friendly products and about $40 \%$ only sometimes). This result is slightly higher than that observed in the previous 2014 study, when $64 \%$ of consumers declared to pay attention to buy products with an increased level of animal welfare. In 2005 the share of Italian consumers paying attention to the welfare/protection of the animals at time of purchasing meat was lower $(20 \%$ most of the times and 31\% sometimes) (EC, 2005).

A further question analyzed the role of animal welfare in affecting purchasing choices. Consumers were asked to assign a score from 0 to 10 (with $0=$ "not at all" and $10=$ "extremely") to the importance they attributed to animal welfare at time of purchasing. Most respondents $(82 \%)$ chose a value equal or above 6 (average score: 7.5), and $25 \%$ of consumers assigned a score of 10 (maximum importance), while only $18 \%$ assigned a score from 0 to 5 .

In our study the income range of the interviewees slightly affected the importance attributed to animal welfare in an unexpected way. About one third (27\%) of those who had an annual income below $10,000 €$ assigned a score of 10 , similarly to the highest income class (over 75,000€; $33 \%$ ). In contrast, only $2 \%$ of the lower income range gave no importance to animal welfare in their purchasing choices, compared to the higher income range where $4.8 \%$ assigned a score of 0 . In the intermediate ranges (from 11.000 to $75.000 €$ ) there were no evident trends in consumers' attitudes. From these data it could be deducted that the income level would have only a marginal effect on the importance that consumers give to animal welfare. In this sense, this result does not agree with previous findings (EC, 2005) in which unemployed people and students appeared to be the least concerned. In our study, these same categories assigned an average score of 8.1 to animal welfare, i.e. a value only slightly lower than the general average (8.4) and in any case higher than that of other theoretically richer categories (entrepreneurs score of 7.9 and managers score of 8.0). This result could be very interesting in the light of a possible trend reversal in the correlation between consumers' income and the importance assigned to animal welfare at the time of purchasing. There is wide consensus in the literature that women, younger participants, pet owners, and those who had spent longer in education and had higher income rates showed the highest concern and were more likely to be willing to pay for welfare-friendly products (Alonso et al., 2020). Therefore, the sensitivity toward animal welfare and other ethical issues is both a matter of education (i.e., instruction level) and individual consciousness (as affected also by socio-demographic characteristics). In our study, it is possible that the high education level observed between the interviewees, together with the high availability of good quality public education institutions in Italy, without quality differentiations with private schools (Bertola et al., 2017), may have had a role in determining the lack of correlation between income and concern for animal welfare. Another, merely specula-

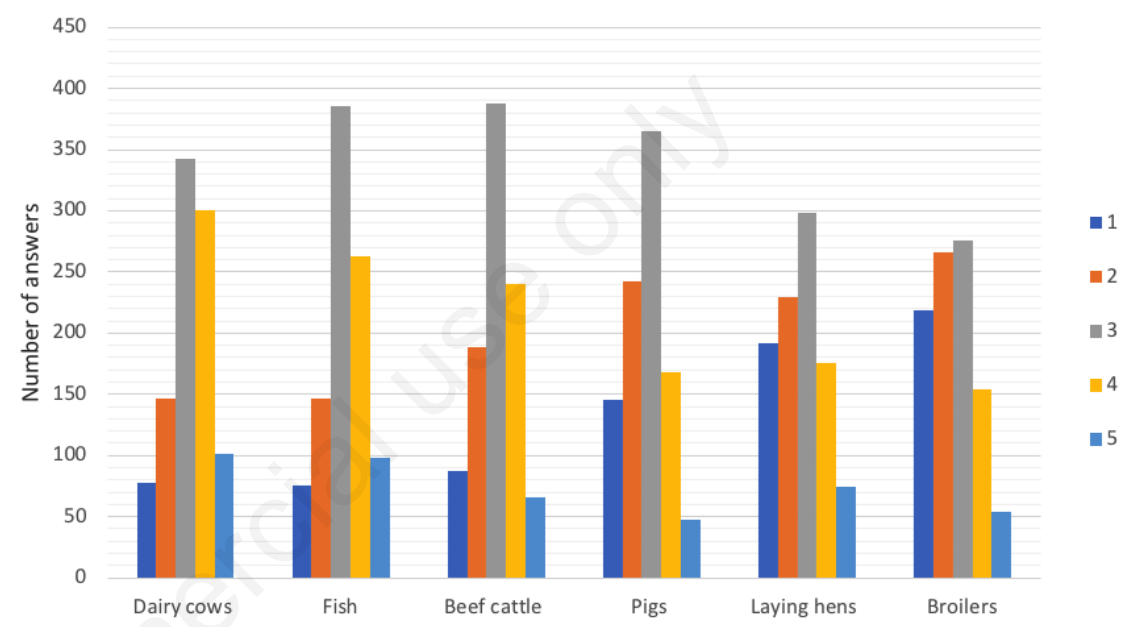

Figure 1. Answers to the question: Please evaluate on a 1-to-5 scale (where 1=minimum welfare; 5= maximum welfare) the level of welfare of the following species on farm.

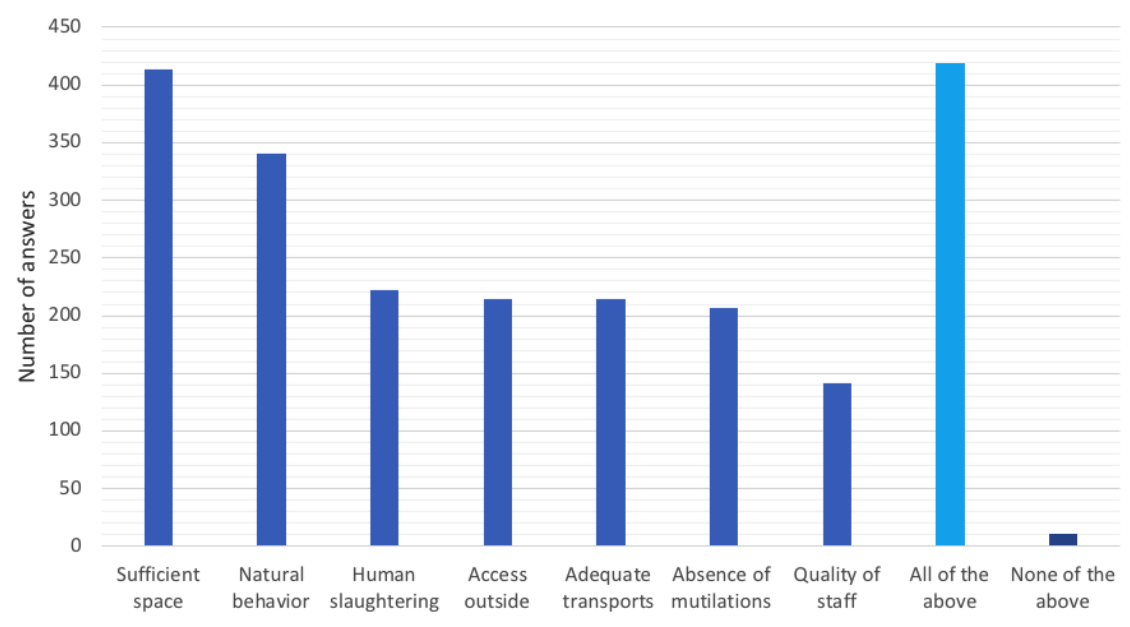

Figure 2. Answers to the question: Which, among these aspects, are the most important in determining the level of animal welfare? (Multiple answers allowed). 
tive, factor, which however cannot be substantiated by objective data, may concern the truthfulness of the annual income declared by the interviewees. Regardless of the impossibility of verifying such data, any false claims would represent a systematic error that would affect the entire sample without substantially changing the result. Furthermore, the tax gaps in Italy are due for the vast majority to VAT (mainly by selfemployed workers), and to IRPEF evasion (by self-employed workers and entrepreneurs) (Senate of the Republic, 2021), categories which represent, on the whole, a limited share of our sample (about $10 \%$ ). However, even if the disposable income does not seem to directly influence the sensitivity and perception of consumers, it undeniably impacts on the real possibility of purchasing animal-friendly foods. In this framework, Clark et al. (2017) highlighted that younger respondents were more willing to spend more for animal welfare, although presumably they had less availability, and that this attitude decreased as age increased.

Despite the purchasing habits declared by the interviewees, it is clearly difficult for consumers to correctly identify animalfriendly products given that, on the European market, labels based on higher animal welfare standards are mainly voluntary and often diversified as there is no harmonized certification covering the whole EU territory. Therefore, communicating to the consumer an additional commitment by the producer on animal welfare may remain problematic. According to the 2005 Eurobarometer surveys (EC, 2005 and 2007), $51 \%$ of European citizens could rarely/never identify such products, with deep differences among countries. To assess Italian consumers' ability to identify animal-friendly products, they were asked to choose from a list which products were, in their opinion, obtained respecting higher animal welfare standards (Figure 3). The list of products included also certification having no relevance to animal welfare. According to interviewees, barn eggs are the products that most respect animal welfare $(59 \%$ of answers), followed by antibiotic-free products $(51 \%)$, private labels certifying higher welfare standards (49\%), products certified as PDO (Protected Designation of Origin)/PGI (Protected Geographical Indication) (45\%) and organic products $(41 \%)$. Products obtained from extensive farming (19\%) and biodynamic agriculture (14\%) are considered much less impacting on animal welfare. Similar values were reported for PDO, PGI and organic products in the previous 2014 study. The discrepancy between the shares of consumers indicating organic products $(41 \%)$ and extensive farming (19\%) as animal friendly indicates the persistence of a certain degree of linguistic confusion, with consumers regarding the concept of 'extensive farming' as less animal-friendly than the organic method, even though the organic method is a regulated example of extensive farming. It is therefore thinkable that the meaning of the adjective 'extensive' has not been fully understood or, alternatively, that the word 'farming' is perceived as something restrictive and coercive per se. It is likely that consumers did not consider that in extensive systems animals have higher space allowances and are normally allowed outdoor access (thus meeting the expectations of consumers in terms of factors mostly affecting animal welfare). It is also very interesting to note that in the previous study the majority of respondents $(65 \%)$ indicated 'non-intensive farming' as a high- welfare system. It is therefore arguable that consumers may have attributed to the negative particle 'non', placed before the term 'intensive', a prevailing role in comparison with the term 'extensive' used in the present study. This latter consideration emphasizes, for this kind of surveys,

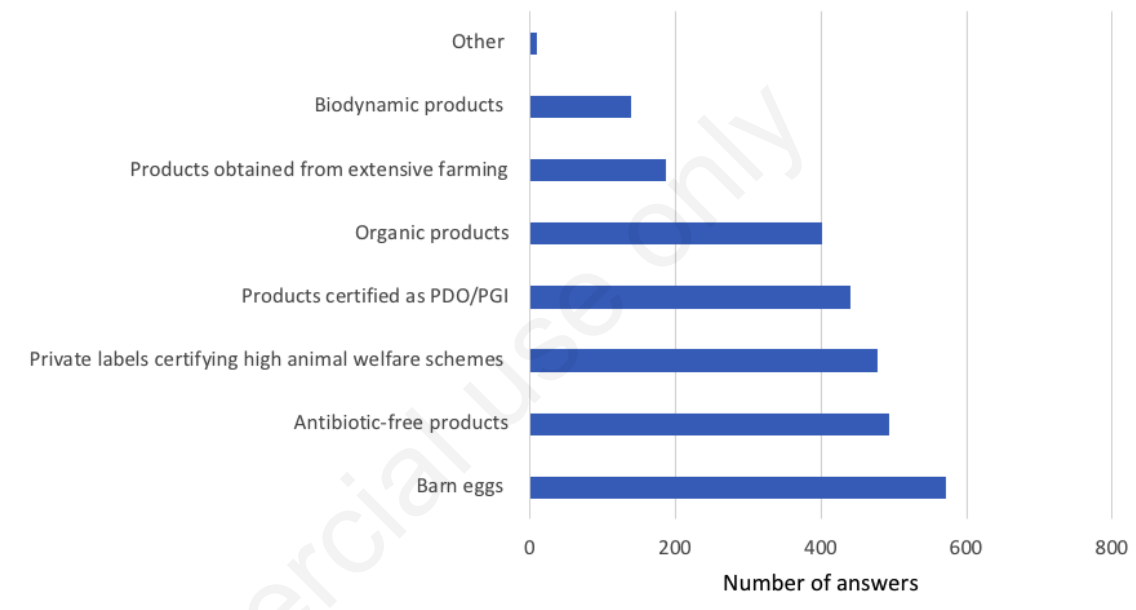

Figure 3. Answers to the question: What products are obtained respecting high animal welfare standards? (Multiple answers allowed).

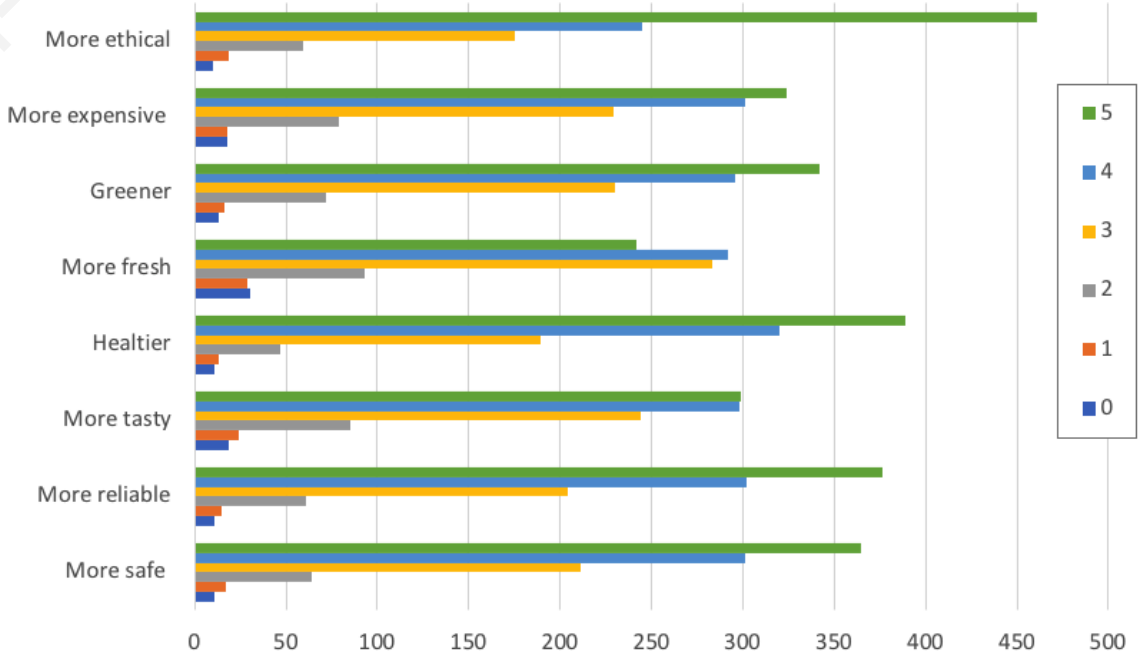

Figure 4. Answers to the question: Please indicate the degree of agreement/disagreement with each of the following statements: Products obtained respecting high animal welfare standards are also... ( $0=$ completely disagree; $5=$ completely agree $)$. 
the importance of the way the question is formulated and its influence on the corresponding answer. It is worth noting that more than one half of the respondents associated a greater welfare level with products deriving from 'antibiotic free' systems. This percentage is higher than that reported in the previous 2014 study (40\%) and it may be related to the growing concern about the problem of antibiotic-resistance which, in recent times, has been widely brought to the attention of the public. It is therefore arguable that Italian consumers may not be fully aware that also the organic method strongly discourages and limits the use of allopathic drugs. Furthermore, organic farming guarantees better conditions than conventional systems for satisfying the physiological, ethological, and developmental demands of animals (Scozzafava et al., 2019). Despite of all the afore-mentioned considerations, organic products are deemed less respectful of animal welfare than other certified foods (such as PDOs and PGIs) which often do not include in their regulations specific elements indicating animal protection levels beyond the minimum requirements established by law. This attitude could be explained by the fact that, at a communication level, organic productions have generally mainly focused on food safety rather than on animal welfare level and health (Martelli et al., 2010). Another hypothesis is that consumers may think that the organic production is strictly addressed to the production of foods of vegetable origin instead of being also applied to animal rearing.

When invited to indicate the characteristics that differentiate animal-friendly from conventional products (Figure 4), about one half of the respondents assigned the highest score (5) to their higher ethical content (48\%), followed by higher healthiness $(40 \%)$, safety and reliability (38\%), and environmental sustainability (greener: $35 \%$ ). These results confirm the existence of a perceived link between ethics and food safety. However, the higher price of animalfriendly products, that from a practical standpoint cannot be disregarded due to its possible negative impact on actual purchasing behavior, was pointed out by more than one third of the interviewees.

\section{Conclusions}

With the exception of improved knowledge on the legislation on animal protection and of increased interest toward animal welfare and related issues (demonstrated also by lower-income consumers), our findings on a large sample of Italian consumers basically confirm those reported in a previous, local survey (Di Pasquale et al., 2014).

The issue that remains unsolved is that related to a lack of ability in correctly identifying products obtained following animal welfare standards above the minimum mandatory levels, i.e. animal-friendly foods.

The problem is further complicated by the observed lack of knowledge on nonconventional rearing systems (extensive farming and organic method). These latter should theoretically meet consumer expectations in terms of space availability and expression of the behavioral repertoire of animals thus leading to a higher level of perceived/actual animal welfare. It is therefore advisable that, in order to fill this knowledge gap, the population should be made aware of different farming systems and a more transparent and less heterogeneous labelling approach should be adopted.

\section{References}

Alonso ME, González-Montaña JR, Lomillos JM, 2020. Consumers' Concerns and Perceptions of Farm Animal Welfare. Animals 10:385

Bennett R, Kehlbacher A, Balcombe K, 2012. A method for the economic valuation of animal welfare benefits using a single welfare score. Anim Welfare 21:125-30.

Bertola G, Checchi D, Oppedisano V, 2007. Private School Quality in Italy. Institute for the Study of Labor. Available at: http://ftp.iza.org/dp3222.pdf [accessed 17/06/2021].

Broom DM, 2010. Animal welfare: An aspect of care, sustainability, and food quality required by the public. $\mathrm{J}$ Vet Med Educ 37:83-8.

Clark B, Stewart G, Panzone L, Kyriazakis I, Frewer LJ, 2017. Citizens, consumers and farm animal welfare: A meta-analysis of willingness-to-pay studies. Food Policy 68:112-27.

Di Pasquale J, Nannoni E, Sardi L, Rubini G, Salvatore R, Bartoli L, Adinolfi F, Martelli G, 2019. Towards the abandonment of surgical castration in pigs: How is immunocastration perceived by Italian consumers? Animals-Basel 9:198

Di Pasquale J, Nannoni E, Del Duca I, Adinolfi F, Capitanio F, Sardi L, Vitali M, Martelli G, 2014. What foods are identified as animal friendly by Italian consumers? Ital J Anim Sci 13:782-9.

Council of the European Union, 2020. Council Conclusions on an EU-wide animal welfare label. General
Secretariat of the Council, Reference number 13691/20. Available at: https://data.consilium.europa.eu/doc/do cument/ST-13691-2020-INIT/en/pdf [Accessed 25/09/2021]

European Commission (EC), 2005. Attitudes of consumers towards the welfare of farmed animals. Special Eurobarometer, 229, Wave 63.2 Available at: https://europa.eu/eurobarometer/surveys/detail $/ 450$ [accessed: 25/09/2021]

European Commission (EC), 2007. Attitudes of consumers towards the welfare of farmed animals Wave 2. Special Eurobarometer 229, Wave 64.4. Available at: http://www.cvzv.sk/DBWelfare/vseob/sp_barometer_fa_en.pdf [accessed: 25/09/2021]

European Commission (EC), 2016. Attitudes of s Towards Animal Welfare. Special Eurobarometer, 442, Wave EB84.4. Available at: https://europa. eu/eurobarometer/surveys/detail/2096 [accessed: 25/09/2021]

European Union (EU), 2018. Regulation (EU) $2018 / 848$ of the European Parliament and of the Council of 30 May 2018 on organic production and labelling of organic products and repealing Council Regulation (EC) No 834/2007. Off J Eur Union L150:1-92.

FAWC (Farm Animal Welfare Committee), 2014. Independent report on evidence and the welfare of farmed animals, part 1, the evidence base. Available at: https://www.gov.uk/government/publications/fawc-report-on-evidence-andthe-welfare-of-farmed-animals-part-1the-evidence-base [Accessed 25/09/ 2021]

Goldberg AM, 2016. Farm animal welfare and human health. Curr Environ Health Rep 3:313-21.

ISTAT (National Institute of Statistic), 2019. Regione Emilia Romagna statistica factbook. Available at: https://statistica.regione.emilia-romagna.it/factbook/fb/economia/pil_p_c [Accessed 25/09/2021]

ISTAT (National Institute of Statistic), 2018. https://www.istat.it/ [accessed: 31/12/2020]

Mancini MC, Menozzi D, Arfini F, Veneziani M, 2018. How do firms use consumer science to target consumer communication? The case of animal welfare, In: Cavicchi A, Santini C, eds. Case studies in the traditional food sector, 1st ed., Woodhead Publishing, Kidlington, UK, pp 337-357.

Martelli G, Valla H, Bucci D, Zaghini G, Vignola G, Sardi L, 2010. Assessment of welfare and productive performance 
in dairy cows organically reared in plains or hilly areas. Anim Welfare 19:17-23.

Miele M, Parisi V, 2001. Consumer concerns about animal welfare and food choice- Report on focus groups. Available

at:

https://ec.europa.eu/food/sites/food/file s/animals/docs/aw_arch_hist_it_fair_fo cus_groups_rep_en.pdf [accessed: $31 / 12 / 2020]$

Norwood FB, Lusk JL, 2011. Social desir- ability bias in real, hypothetical, and inferred valuation experiments. Am J Ag Econ 93:528-34.

Scozzafava G, Gerini F, Boncinelli F, Contini C, Marone E, Casini L, 2020. Organic milk preference: Is it a matter of information? Appetite 144:104477.

Senate of the Repubblic, 2021. Taxation in Italy: an overview. Servizio studi Ufficio per le ricerche nei settori economico e finanziario. Available at: http://documenti.camera.it/leg18/dossie
r/pdf/FI0141_EN.pdf [Accessed: 25/09/ 2021]

Torquati B, Taglioni C, Cavicchi A, 2015. Evaluating the $\mathrm{CO} 2$ emission of the milk supply chain in Italy: An exploratory study. Sustainability-Basel 7:7245-60.

Vanhonacker F, Verbeke W, 2014. Public and consumer policies for higher welfare food products: Challenges and opportunities. J Agr Environ Ethic 27:153-71. 